\title{
Huge Congenital Thymic Cyst with Microscopic Thymoma
}

\author{
Alberto Terminella ${ }^{1}$, Giacomo Cusumano ${ }^{1 *}$, Ignazio $\operatorname{Vasta}^{1}$, Rosalia Giarlotta ${ }^{1}$, Salvatore Bellofiore $^{1}$, \\ Carmelo Riscica Lizzio ${ }^{1}$, Salvatore Saita ${ }^{1}$, Maria D'Arrigo ${ }^{2}$ \\ ${ }^{1}$ Division of General Thoracic Surgery, "Vittorio Emanuele-Policlinico" Hospital, Catania, Italy \\ ${ }^{2}$ Department of Histopathology, "Vittorio Emanuele_Policlinico" Hospital, Catania, Italy \\ Email: "giacomare55@hotmail.com
}

Received November 13, 2012; revised December 20, 2012; accepted December 28, 2012

Copyright (C) 2013 Alberto Terminella et al. This is an open access article distributed under the Creative Commons Attribution License, which permits unrestricted use, distribution, and reproduction in any medium, provided the original work is properly cited.

\begin{abstract}
The congenital thymic cysts are rare. They have a congenital origin and they are benign. The differential diagnosis of acquired cysts, cystic thymoma and thymic malignancies in cystic degeneration can be particularly difficult. Rarely, they assume clinical relevance for the appearance of symptoms of compression, more typical of malignant lesions, and the association with thymoma was reported in very few cases in literature. For all these features, treatment strategy remains controversial and in particular surgical approach. We report a case of a huge symptomatic congenital thymic cyst, surgically removed with histological finding of microscopic thymoma.
\end{abstract}

Keywords: Thymic Cystis; Thymoma; Mediastinal Tumor; Surgery

\section{Case Report}

A 40-year-old woman was admitted to our hospital with worsening dyspnoea and chest pain. Her medical history revealed a previous percutaneus aspiration of mediastinal cyst, which occurred 5 years before, physical examination, and laboratory findings were normal. The chest $\mathrm{X}$-ray showed an upper mediastinal enlargement. The CT scan revealed a homogenous mediastinal cystic lesion, with approximately maximal diameter of $20.2 \mathrm{~cm}$. The cyst occupies the anterior mediastinum and the anterior-lower space of both hemithorax, without evidence of infiltration of surrounded tissues (Figure 1).

The clinical and radiological presentation and the previous history, direct our choice to a symptomatic "relapse of thymic cyst" and to the decision of surgical approach. Patient underwent radical transternal thymectomy through an inframammary 10 centimetres vertical cutaneus incision. Surgical exploration revealed a well-encapsulated cystic bilobe formation $17 \times 16 \times 11$ centimetres with thin cystic wall within the right inferior lobe of the thymus. The cystic contains a serous liquid. Postoperative time was uneventful.

Histological examination revealed that cysts were partially lined by small cuboidal cells with fibrous-adipoose thin wall, which focally showed thickening containing small foci of lymphoid tissue with Hassal bodies (Fi-

${ }^{*}$ Corresponding author. gure 2A). Between the cyst and the thymic horn, a small area was found with neoplastic thymic elements composed of spindled to oval epithelial cells with large nucleus and evident nucleulus nucleolus. The pathological diagnosis was thymoma in pre-existing thymic cyst (Figure 2B).

\section{Discussion}

Benign thymic cysts represent approximately $1 \%$ of all anterior mediastinal masses. They can be congenital or acquired, unilocular or multilocular and frequently, they are asymptomatic. Congenital cysts are usually unilocular with thin walls lined by squamous or small columnar cells and containing clear fluid; they show no evidence of inflammation. They probably origin originate from fetal thymopharyngeal tract. While, acquired cysts, result from an inflammatory process, are often multiloculated, contain chocolate colored fluid or gelatinous material and they have thick fibrous walls characterized by inflamematory process [1-3].

Cystic thymoma and cystic degeneration of the larger thymoma are common, exceptional thymomas is found in the contest of the cyst, especially in congenital cysts ones in which arise from the cystic wall, suggesting that neoplastic change could occur in a simple thymic cyst [4-6]. In summary, thymoma occurs even in case of congenital thymic cyst. 

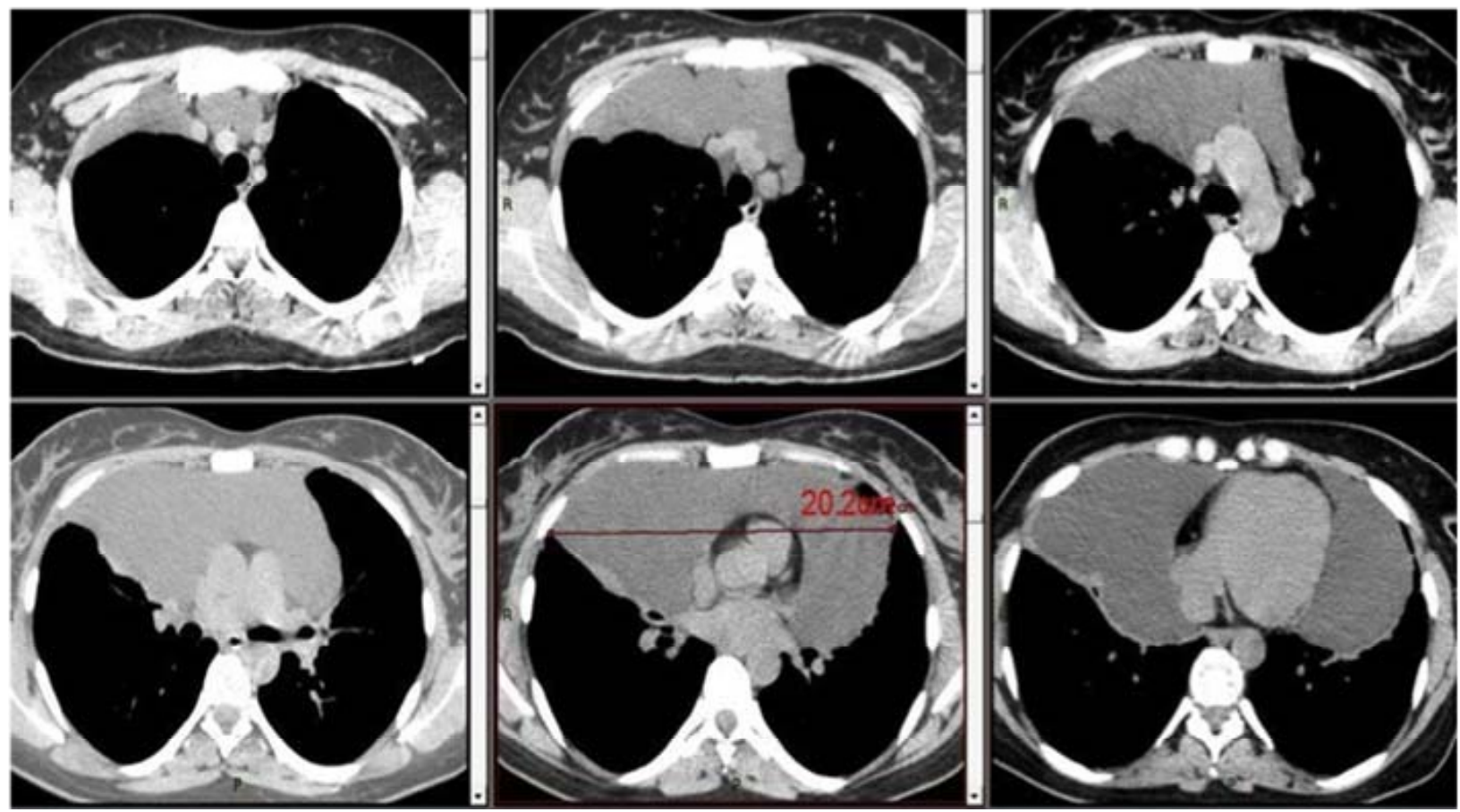

Figure 1. Thorax CT scan: homogenous mediastinal cystic lesion that occupies the anterior mediastinum.

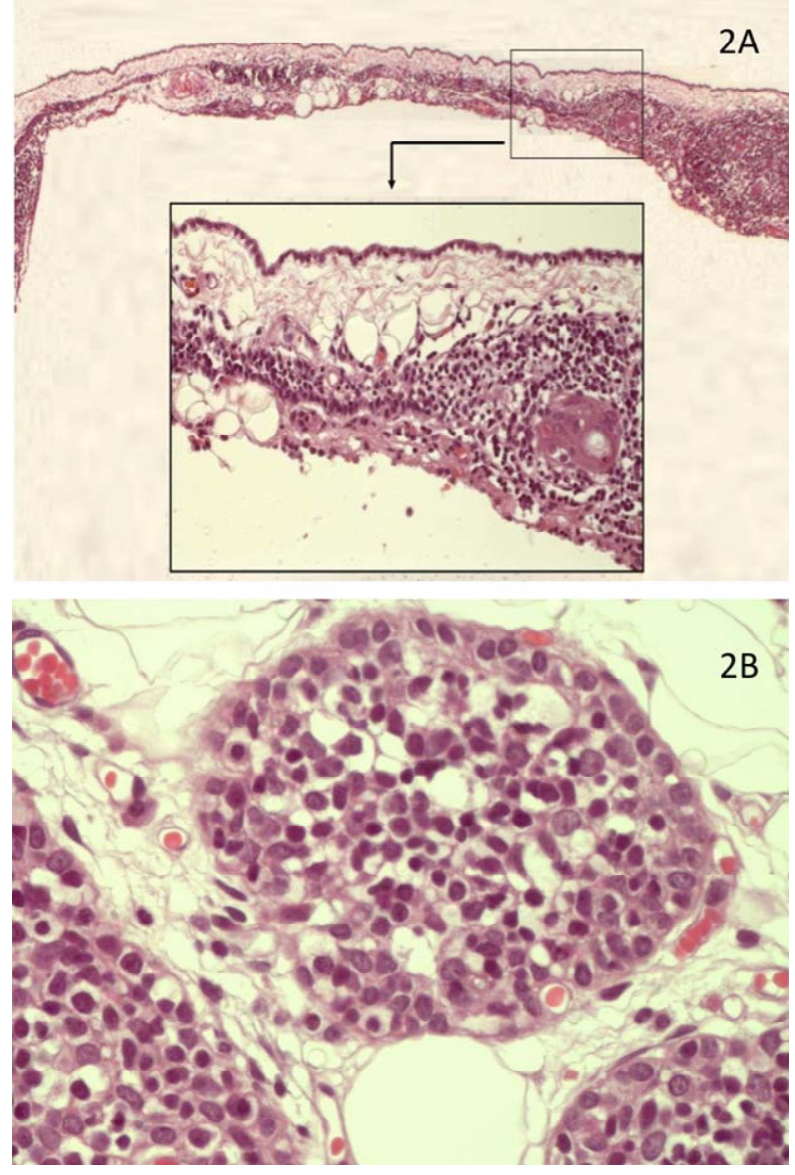

Figure 2. (2A) Microscopic findings of the specimen show a congenital cyst lined with squamous or cuboidal epithelium; (2B) Histological finding of microscopic thymoma. 
Our case confirms the possible onset of microscopic foci of thymoma in the context of congenital cyst but the role of this last in the onset of thymoma is still not clear. Our case strengthens the need of a follow-up, even in case of congenital cysts and raises the question of a possible surgical treatment in this group of patients.

\section{REFERENCES}

[1] R. A. Indeglia, M. A. Shea and T. B. Grage, "Congenital Cysts of the Thymus Gland," Archives of Surgery, Vol. 94, No. 1, 1967, pp. 149-152. doi:10.1001/archsurg.1967.01330070151030

[2] M. Rahmati, P. Corbi, H. Gibelin, C. Jayle, M. Abdou, S. Milinkevitch, P. Menu and J. L. Kraimps, "Management of Thymic Cysts," Annales de Chirurgie, Vol. 129, No. 1, 2004, pp. 14-19. doi:10.1016/j.anchir.2003.11.004
[3] S. Suster and J. Rosai, "Multilocular Thymic Cyst: An Acquired Reactive Process. Study of 18 Cases," The American Journal of Surgical Pathology, Vol. 15, No. 4, 1991, pp. 388-398. doi:10.1097/00000478-199104000-00008

[4] N. H. Dyer, "Cystic Thymomas and Thymic Cysts, a Review,” Thorax, Vol. 22, No. 5, 1967, pp. 408-421. doi:10.1136/thx.22.5.408

[5] K. Sugio, K. Ondo, M. Yamaguchi, K. Yamazaki, S. Kase, F. Shoji and K. Sugimachi, "Thymoma Arising in a Thymic Cyst," Annals of Thoracic and Cardiovascular Surgery, Vol. 6, No. 5, 2001, pp. 329-333.

[6] T. Papadas, P. A. Dimopoulos, F. Sampsonas, N. Mastronikolis, K. Spiropoulos and P. D. Goumas, "Cystic Thymoma Coexisting with Vascular Dysplasia," European Review for Medical and Pharmacological Sciences, Vol. 12, No. 5, 2008, pp. 335-338. 